\title{
Wilson Disease with Hepatic Impairment and Thrombocytopenia: A Case Report
}

\author{
Krishnan Karthickeyan*, Chegireddy Mahindranath Reddy, Jahangeer Batcha Noor Mohamed, Kothagundu Vaibhavi \\ Department of Pharmacy Practice, SRM College of Pharmacy, SRM Institute of Science and Technology, Kattankulathur, Kanchipuram, Tamil Nadu, INDIA.
}

\begin{abstract}
Introduction: Wilson disease is a rare autosomal recessive disorder. The Case report describes the penicillamine induced thrombocytopenia. Case Report: A 14-year-old girl presented with previously diagnosed with Wilson disease treated with penicillamine and pyridoxine. Complaints of dyskinesia, slurred speech, severe hyperbilirubinemia and prominent extrapyramidal features consisting of the rigidity, tremors and ophthalmic examination of her eyes reveal the Kayser-Fleischer ring and sunflower cataract and low blood count. Conclusion: Wilson disease is a rare inherited disorder. Approximately $30 \%$ of the patient cannot tolerate penicillamine due to early hypersensitivity or bone marrow suppression or renal failure occurs due to the failure of therapy. Hence zinc is considered an alternative therapy for
\end{abstract}

pediatric patients.

Key words: Wilson disease, Thrombocytopenia, Hepatic impairment, Penicillamine, Zinc.

\section{Correspondence}

Mr. Krishnan Karthickeyan, Assistant Professor, Department of Pharmacy Practice, SRM College of Pharmacy, SRM Institute of Science and Technology, Kattankulathur - 603203, Tamil Nadu, INDIA.

Phone: +91 9841910057

Email: karthickeyank@hotmail.com

DOI: 10.5530/jyp.2018.10.82

\section{INTRODUCTION}

Wilson disease is a rare inherited autosomal recessive disorder caused by a mutation in the ATP7B gene on chromosome $13 \mathrm{q} .{ }^{1}$ Copper is an essential trace element which encodes a membrane-bound, ATP bound, copper-transporting ATPase. ATP7B protein deficiency impairs biliary copper excretion, resulting in positive copper balance, hepatic copper accumulation, and copper toxicity from oxidant damage. In the earlier stage, copper accumulates in the cytosol of the hepatocytes, thus including synthesis of the metallothionein and copper bound metallothionein ends up in lysosomes. High copper levels include hepatocytes necrosis, followed by increased copper release into the bloodstream, leading to hemolysis and accumulate in kidney, brain, and cornea. In the later, copper accumulation produces pigmented rings namely Kayser-Fleischer ring which represents the hallmark of the diagnosis, later stages deposition of the copper occurs in the basal ganglia, resulting in gliosis and neuronal loss. ${ }^{2}$ CT scan and MRI reveals the damage in the basal ganglia and other parts of the brain like thalamus, pons, medulla, cerebellum. ${ }^{3}$ Progressive neurodegeneration leads to neurological symptoms including tremor, dystonia, slurring of speech and rigidity behavioral disturbances are also present with changes in personality, depression, and schizophrenia. Although liver symptoms are most common in affected children, neurological disturbances are most typical adult onset of the disease. Increase levels of the liver copper are the result of impaired biliary excretion of the metal. ${ }^{2}$ Prevalence is usually occurring 1 in $30000-40000 .^{3-4}$

\section{CASE REPORT}

A 14-year-old female patient of previously diagnosed with Wilson disease was admitted in neurology ward with a complaint of involuntary movement of both upper limbs for 4-5 months, speech difficulty history of joint pain, gum bleeding present. On physical examination aphasia is present. Extra ophthalmic examination reveals the presence of Kayser-Fleischer ring, Sunflower cataract for both eyes. Complaints of difficulty in swallowing, complaints of the episodic stiffness of calf muscle. Family history reveals born to non-consanguineous parents and birth history
Table 1: Results of the complete blood count during hospitalization.

\begin{tabular}{ccccc}
\hline Tests & $\begin{array}{c}\text { Day-3 } \\
\text { (values) }\end{array}$ & $\begin{array}{c}\text { Day-4 } \\
\text { (values) }\end{array}$ & $\begin{array}{c}\text { Day-5 } \\
\text { (values) }\end{array}$ & $\begin{array}{c}\text { Day-8 } \\
\text { (values) }\end{array}$ \\
\hline Hemoglobin & 9.0 & 9.0 & 10.2 & 9.4 \\
Total WBC count & 1300 & 1400 & 1700 & 1800 \\
neutrophils & 59 & 59 & 64 & 64 \\
lymphocytes & 35 & 31 & 27 & 23 \\
eosinophil's & 05 & 06 & 06 & 06 \\
monocytes & 03 & 04 & 03 & 02 \\
Total RBC count & 3.0 & 3.0 & 3.4 & 3.1 \\
PCV & 29 & 28 & 32 & 29 \\
Platelet count & 70000 & 25500 & 65000 & 45000 \\
MCV & 93 & 92 & 93 & 94 \\
MCH & 29 & 29 & 29 & 30 \\
MCHC & 32 & 31 & 32 & 32 \\
\hline
\end{tabular}

Note: WBC-white blood count, RBC-red blood count, PCV-packed cell volume, $\mathrm{MCV}$-mean corpuscular volume, $\mathrm{MCH}$-mean corpuscular hemoglobin, $\mathrm{MCHC}$ mean corpuscular hemoglobin count

uneventful. Treatment history includes first-line therapy of penicillamine with combination of pyridoxine was administered. Urine analysis shows the pale yellow colour, turbid in appearance, specific gravity. Table 1 shows RBC (2-4 cells), pus cells (1-2), Calcium oxalate crystals are present in urine sample.

\section{Peripheral smear impression}

Report: Normocytic, Normochromic anemia, Leucopenia with neutrophilic preponderance and Eosinophilia with severe thrombocytopenia.

\section{Ultrasound report}

Impression: Parenchymal liver disease with splenomegaly and perispleniccollaterate 
Table 2: Results of liver function test and plasma thrombin time during hospitalization.

\begin{tabular}{cccc}
\hline tests & value & test & value \\
\hline Total bilirubin & 2.5 & GGT & 37 \\
Direct bilirubin & 0.8 & APTT-Test $(\mathrm{sec})$ & 31 \\
Total protein & 5.1 & APTT-Control (sec) & 36 \\
Albumin & 2.1 & PTT-Test $(\mathrm{sec})$ & 13 \\
Globulin & 3.0 & PTT-control $(\mathrm{sec})$ & 18 \\
AST & 98 & INR-Ratio & 1.36 \\
ALT & 47 & & \\
Alkaline phosphate & 137 & & \\
\hline
\end{tabular}

Note: AST- Aspartate Transaminase, ALT-Alanine Transaminase, GGT-Gamma Glutamyl Transaminase, APTT-Activated Partial Thromboplastin Time, PTTPartial Thromboplastin Time, INR-International Normalized Ratio.

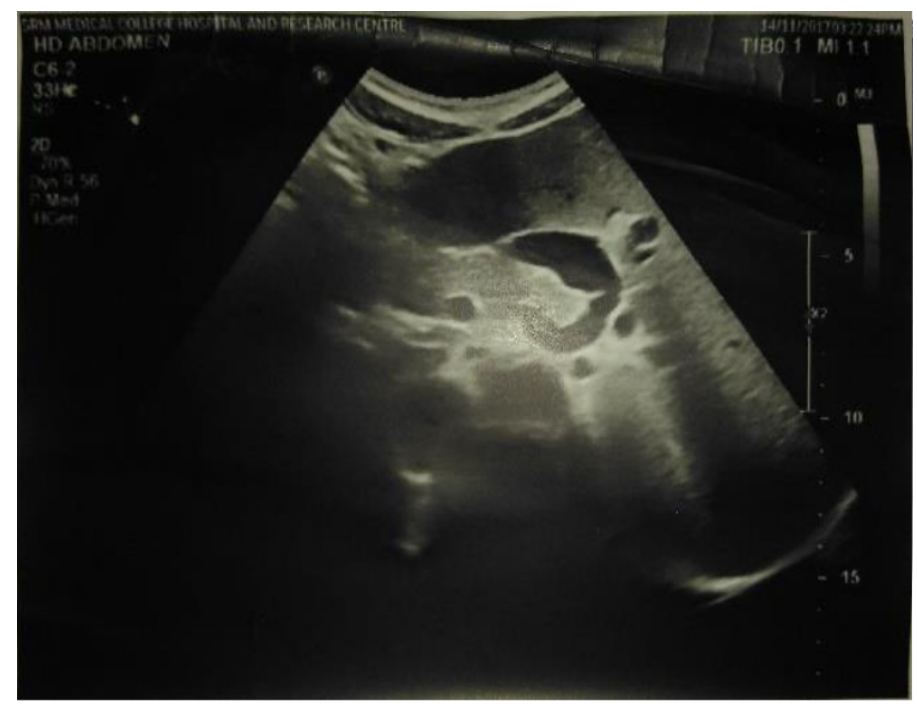

Figure 1: Liver shows the parenchymal liver disease

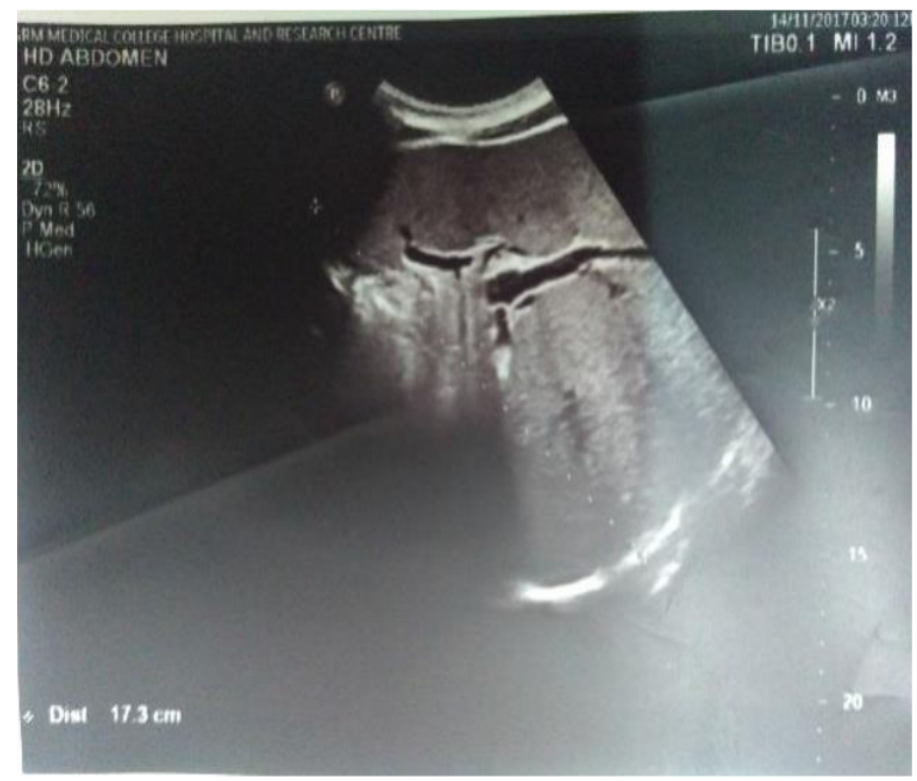

Figure 2: Spleen shows the splenomegaly and perisplenic collaterate

\section{DISCUSSION}

The hepatic abnormalities are diagnosed earlier than the neuropsychic findings because of the blood brain barrier protect the central nervous system for some years. ${ }^{5}$ The clinical features of the Wilson disease may present as hepatitis, cirrhosis or hepatic decompensation. Neurological features show three main movement disorders include dystonia, incoordination, and tremors. The patient had conjugated hyperbilirubinemia and ultra sound report reveals the splenomegaly and another metabolic function of the liver is abnormal such as the ALT is 47 . The upper limit of the aminotransferase is 35 in children increased level indicate the chronic liver disease. ${ }^{6}$ Other laboratory data shows the biliary obstruction.

The neurological presentation of Wilson disease contains two faces movement disorder or dystonia. Movement changes contain tremor, incoordination, fine motor changes. Dystonia has a symptom of mask face, rigidity, and gait disturbances and the remission of Parkinson. Along with other complications like drooling, difficulty in swallowing particularly in elder patients and psychiatric complications like schizophrenia also present. ${ }^{4}$ The other neurological symptoms observed in the patient are dysarthria, tremor, dystonia and an emotional abrupt with laughing, difficulty in swallowing.

Diagnosis of Wilson disease is based on numerous clinical findings, including neurological, elevated liver disease the presence of KayserFleischer rings, prolongation of the prothrombin time. USG abdomen shows the Parenchymal liver disease with spleenomegaly and Perisplenic collaterate are help in the diagnosis of the Wilson disease. But the patient is previously diagnosed and on treatment with D-Penicillamine. Penicillamine is used as the chelating therapy, it increases urinary excretion of copper resulting in negative copper balance. But in some cases, side effects are noted such as bone and joint deformity, thrombocytopenia, skin rashes and persistent abdominal pain leukocytopenia. ${ }^{3,7-8}$ Other investigation like MRI reveals the brain lesions with excellent copper clearance. ${ }^{9}$ Here the patient is not tolerated with D- Penicillamine therapy, it shows some side effects like thrombocytopenia, bone marrow suppres sion and elevated protein urea. The laboratory report shows a decrease in the complete blood count and thrombocytopenia is noticed. Penicillamine is discontinued.

In recent years Zinc has been used as the alternative to D-Penicillamine for Wilson disease. The advantage of the Zinc therapy is less toxic as compared to that of Penicillamine. In some studies, shows the Zinc therapy after intolerance to Penicillamine shows response to change in hepatosplenomegaly. ${ }^{10}$ Zinc acts by blocking the absorption of copper by inducing intestinal cell metallothionein. ${ }^{4}$ The recommended dose for Zinc therapy is $25 \mathrm{mg}$ thrice a day as an initial dose after then switch to the standard dose of $50 \mathrm{mg}$ thrice a day. ${ }^{11}$

\section{CONCLUSION}

In this case, the patient received the Penicillamine as initial therapy which leads to the side effects like thrombocytopenia and bone marrow suppression. Hence as a Clinical pharmacist, we recommended Zinc is considered to be alternate and first line therapy for the patients who do not tolerate for the Penicillamine, which is less toxic as compare to that of Penicillamine along with the other supportive therapy, which is needed for the better treatment outcome for the patient.

\section{REFERENCES}

1. Bull PC, Gordon R, Thomas JM, Rommens JR. Forbes and Diane Wilson Cox The Wilson disease gene is a putative copper transporting P-type ATPase similar to the Menkes gene. Nature Publishing Group. 1993;5(4):327-37.

2. Rotilo G, Ciriola MR, Carri MT, Rossi L. Distribution of copper homeostasis and brain function, In: Massaro, Edward J. Hand Book of Copper Pharmacology and 
Toxicology, $1^{\text {st }}$ edition, Human Press. 2002:277-96.

3. Brewer J. George, Harrison's Principle of Internal Medicine. In: Ioscalzon, Fauci Braunwald Kasper, Hauser, Longo, Jameson, The Mac Grew Hill Publication. 2008:2449-52.

4. Golder N. Wilson, Wilson disease, Rosenberg molecular and genetic basis of neurology and psychiatric disease, $5^{\text {th }}$ edition, Texas, Elsevier. 2015:443-53.

5. Hefter H, Tezayak O, Rosenthal D. Long term outcome of neurological Wilson's disease, Elsevier. 2018;46:1-12.

6. Lamireau T, McLin V, Nobili V, Vajro P. A Practical Approach to the Child with Abnormal Liver Tests. Elsevier. 2014;38(3):259-62.

7. Kalita J, Kumar V, Chandra S, Kumar B. Worsening of Wilson Disease following
Penicillamine Therapy. European Neurology. 2014;71(3-4):126-31.

8. Czlonkowska A, Gajada J, Rodo M. Effects of Long-term Treatment in Wilson's Disease with D-Penicillamine and Zinc sulphate. J Neurol. 1996;243(3):269-73.

9. Brewer GJ, Terry CA, Aisen AM, Hill GM. Worsening of Neurologic Syndrome in Patient with Wilson Disease with Penicillamine Therapy. Arch Neurol. 1987;44(5):490-93.

10. Hoogenraad TU, Hattum JV Van den Hamer CJ Management of Wilson Disease with Zinc sulphate, Experience in Series of 27 Patients, Journal of Neurological Sciences. Elsevier. 1987;77(2):137-46.

11. Brewer GJ, Dick RD, Johnson VD, Brunerg JA, Klulinnd KJ, Flink JK. Treatment of Wilson's disease with Zinc, XV Long- term Follow-up Studies. J Lab Clin Med. $1998 ; 132(4): 264-78$

Article History: Submission Date : 25-01-2018 ; Revised Date : 08-05-2018; Acceptance Date : 22-06-2018.

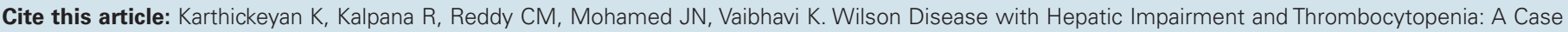
Report. J Young Pharm. 2018;10(3):371-3. 